\title{
Pure Redistribution and the Provision of Public Goods
}

Sausgruber, Rupert; Tyran, Jean-Robert

Publication date:

2006

Document version

Publisher's PDF, also known as Version of record

Citation for published version (APA):

Sausgruber, R., \& Tyran, J-R. (2006). Pure Redistribution and the Provision of Public Goods. Department of Economics, University of Copenhagen. 


\section{DISCUSSION PAPERS \\ Department of Economics \\ University of Copenhagen}

06-24

Pure Redistribution and the Provision of Public Goods

Rupert Sausgruber

Jean-Robert Tyran

Studiestræde 6, DK-1455 Copenhagen K., Denmark

Tel. +45 35323082 - Fax +4535 323000

http://www.econ.ku.dk 


\title{
Pure Redistribution and the Provision of Public Goods
}

\author{
Rupert Sausgruber $^{*}$ and Jean-Robert Tyran ${ }^{* *}$
}

December 2006

\begin{abstract}
We study pure redistribution as a device to increase cooperation and efficiency in the provision of public goods. Experimental subjects play a two-stage game. The first stage is the standard linear public goods game. In the second stage, subjects can redistribute payoffs among other subjects in their group. We find that cooperation and efficiency increases substantially with this redistribution scheme, and that the redistribution option is popular. Our results provide an intuitive explanation for why an imposed redistribution rule, as proposed by Falkinger (1996), is capable of sustaining cooperation in the provision of public goods.
\end{abstract}

Keywords: experiment, public goods, redistribution

JEL-codes: C9, H41

\footnotetext{
* University of Innsbruck, Department of Public Economics, Universitätsstr. 15, A-6020 Innsbruck. Rupert.Sausgruber@uibk.ac.at

*** University of Copenhagen, Department of Economics, Studiestraede 6, DK-1455 Copenhagen.

Jean-Robert.Tyran@econ.ku.dk. We thank Karen Larsen for support and most effective research assistance.
} 
This paper provides an experimental test of the effects of pure redistribution on the provision of public goods. Experimental subjects play a two-stage game. The first stage is the standard linear public goods game. In the second stage, subjects can redistribute payoffs among other subjects in their group, thereby simultaneously rewarding one subject and sanctioning another subject within their group. In the experiment we require that redistribution is budget neutral, i.e. that what is taken from one player must be given to another player. As a consequence, redistribution is costless for society. Moreover, redistribution is a low-cost choice in the sense that it entails no direct material cost or benefit for the decision maker.

We find that pure redistribution strongly improves cooperation. In particular, contributions to the public good are more than three times as high (76\%) with the redistribution option than in a control treatment without the option to redistribute (22\%). We find that subjects use redistribution systematically to punish free riders and reward cooperators. Finally, we show that the option to redistribute is not only efficient, it is also popular. Subjects seem to anticipate the beneficial effects of pure redistribution. When asked to vote on the introduction of the redistribution scheme, $85 \%$ of all groups approve of redistribution.

Our study relates to Falkinger (1996) who suggested that redistribution may improve cooperation in the provision of public goods. In particular, Falkinger proposed an exogenously imposed, budget-neutral redistributive mechanism that subsidizes (i.e. rewards) above-average contributions and taxes (i.e. sanctions) below-average contributions. The tax/subsidy-rate is chosen to make contributions incentive compatible. In laboratory tests, this mechanism has been shown to sustain almost full cooperation (Falkinger et al. 2000). Our results suggest that the basic element of the Falkinger mechanism appeals to widely held fairness concerns.

\section{Experimental Design}

The experiment has two phases with 5 periods each. In phase 1, subjects play a standard linear public goods game in groups of 3 players. Subjects simultaneously decide how much of 20 endowment points to keep or invest into the public good in each period. Payoffs are determined by $\pi_{i}=20-c_{i}+0.5 \sum_{j} c_{j}$, where $c_{i}$ is subject $i$ 's contribution to the public good, and 0.5 is the marginal per-capita return of contributing to the public good. 
The contribution stage is followed by a redistribution stage. In this stage, the contributions of each subject in the first stage are anonymously revealed and each subject can redistribute a maximum of 6 points between the other two subjects in the group. Redistribution is budget-neutral, i.e., the points the decision maker takes from one subject have to be transferred to the other subject in the group. Subject i's payoff now is $\pi_{i}=20-c_{i}+0.5 \sum_{j} c_{j}+\sum_{i \neq j} r_{j}$, where $r_{j}$ denotes the points received from or taken by the other two group members. Because each subject can redistribute at most six points and because there are two other group members for every subject within a group, $\sum_{i \neq j} r_{j}$ is in the range of -12 to 12 .

\section{$3 \quad$ Predictions}

We know from previous research that people systematically use costly sanctions to punish free riders, and that these sanctions induce higher levels of cooperation (Fehr and Gächter 2000). We also know that people are willing to reward cooperative behavior of others even if it is costly to them (Sefton et al. 2002). In one-shot games this behavior suggests that people have a willingness to pay for expressing social preferences, ethical values, or emotions. In our experiment, the decision to redistribute points between others is costless to the decision maker and it is therefore likely that people will make extensive use of "expressive” redistribution.

To illustrate the possible consequences of expressive redistribution, suppose that all subjects hold the belief that everyone in the group will redistribute the maximum of 6 points from low contributors to high contributors for any difference in contributions between other subjects in the group. Such a belief sustains the social optimum of full cooperation as an equilibrium because subjects always have an incentive to contribute marginally more than others, ratcheting contributions up to the maximum level. Of course, different sets of beliefs will sustain different equilibria. A priori, standard theory provides little guidance to predict behavior in this game and it is an empirical question whether redistribution has any effect on efficiency.

\section{$4 \quad$ Results}

A total of 123 subjects participated in six sessions at the University of Copenhagen. Subjects were freshmen economics students who started studying a few weeks before the experiment. They earned DKK 100 ( $\approx$ US\$ 16.5) on average. 
The experiment had three treatments. Treatment $\mathrm{T}(\mathrm{No})$ is a control without redistribution (5 groups), and treatment $\mathrm{T}$ (Redistribute) is with redistribution in phase 2 (16 groups). In treatment $\mathrm{T}$ (Vote), subjects were allowed to vote on the redistribution option before the start of phase 2. If the majority of the group accepted the proposal, phase 2 was implemented with the redistribution option. Otherwise, it was without redistribution as in T(No). 20 groups participated in this treatment.

\subsection{The effects of redistribution}

Figure 1 shows average contributions with and without the option to redistribute, i.e. in treatments $\mathrm{T}$ (Redistribute) and $\mathrm{T}(\mathrm{No})$. We aggregate the data in phase 1 for both treatments as they are identical in this phase. In phase 1, the pattern of contributions replicates the typical findings observed in many public goods experiments: contributions start out at 50 percent of the endowment, followed by a decay over time. In $\mathrm{T}(\mathrm{No})$, the downward trend in average contributions continues after a restart effect in phase 2. In contrast, contributions sharply increase when the redistribution option is available. Averaged over all periods of phase 2, subjects contribute more than three times as much when the option to redistribute is present than when it is not. In T(Redistribute), the average contribution is 15.1 points, while it is only 4.5 points in $\mathrm{T}(\mathrm{No})$. The difference between the treatments is highly significant ( $p=0.003$, two-sided Mann Whitney test).

Figure 1: Average contributions over periods

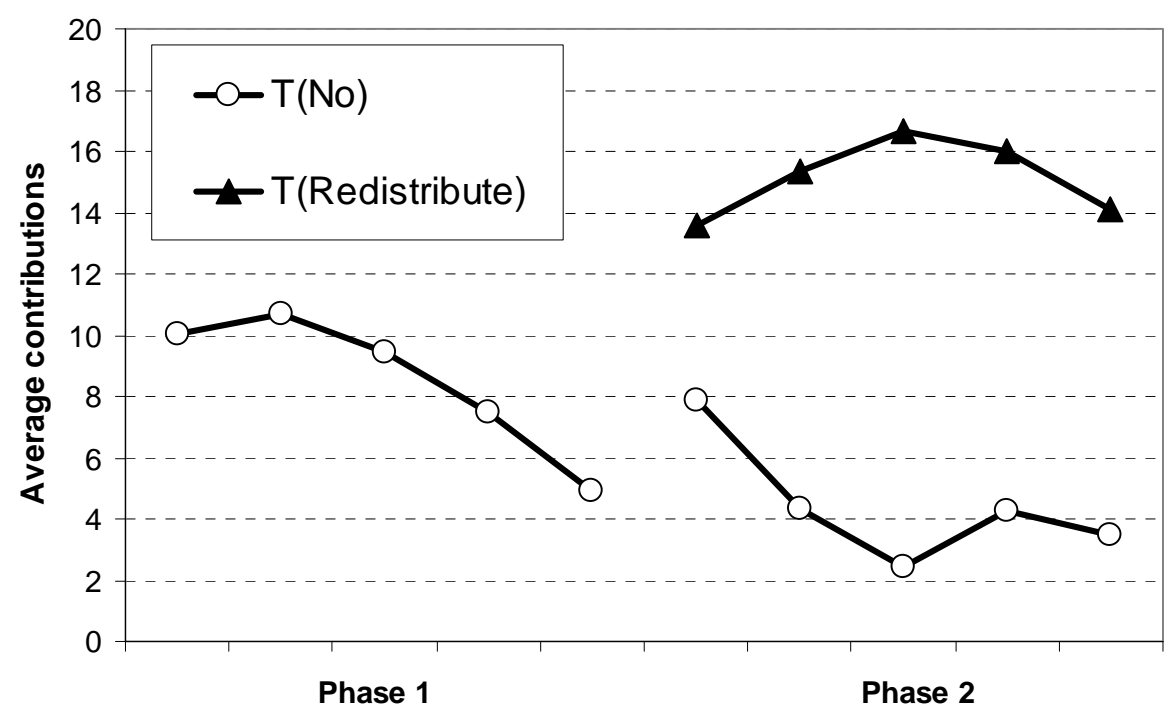




\subsection{The motives of redistribution}

The reason why our redistribution scheme is so effective in increasing cooperation and efficiency is that subjects use the redistribution option, and that they use it in a systematic way. For example, subjects used the redistribution option in 166 out of 240 possible cases. In $71.7 \%$ of these cases, redistribution was in favor of the group member with the higher contribution. In $15.1 \%$ of the cases, redistribution is directed in reverse, and in the remaining $13.3 \%$ of the cases, redistribution is used when there is no difference between the contributions of the other two players.

Figure 2: Net transfer from redistribution for deviations from others' average contributions; $N=$ 240

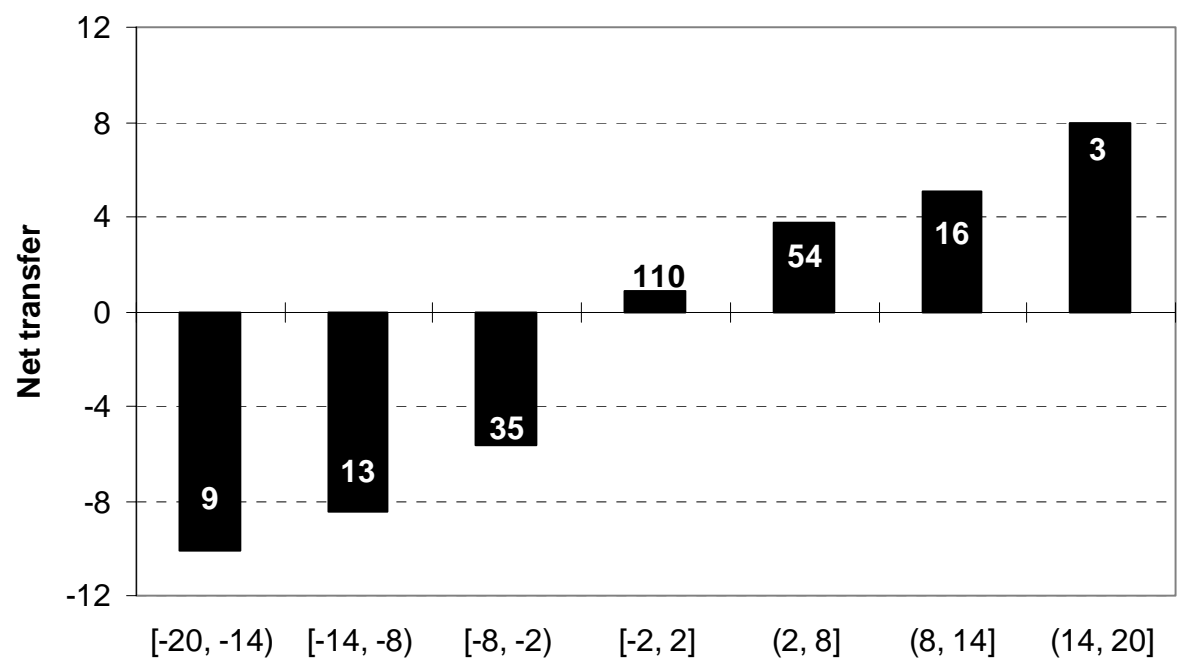

Deviation from average contribution from the other group members

Figure 2 shows the net transfer from redistribution by the deviation from the average contribution of the other group members. The numbers on the bars indicate the number of observations in the respective intervals. The figure reveals that contributions below the group average result in a negative net transfer from redistribution (= punishment), whereas higher than average contributions induce a positive net transfer (= reward). According to an OLS regression ${ }^{1}$, the measure of association between the net transfer and the deviation from the average contribution from the other group members is $0.67(p=0.000)$. Subjects rarely use redistribution

\footnotetext{
1 The regression includes dummies for groups and periods to control for dependence between time and groups. A constant is also included. The coefficient of determination and the F-statistics are $\mathrm{R}^{2}=0.502$ and $F(20,219)=$ 11.03.
} 
when others' contributions are similar (see bar in the range -2, 2). The figure thus shows that subjects use redistribution systematically to punish low contributors at the benefit of high contributors.

\subsection{Voting on the option to redistribute}

The discussion above has shown that pure redistribution enhances cooperation in the provision of public goods and has a pronounced positive effect on efficiency. These results suggest that redistribution is an effective means of overcoming the free-rider problem in public good dilemmas. However, it is not clear that the redistribution scheme is also a socially feasible means to mitigate the free-rider problem for two reasons. First, subjects may underestimate the beneficial effects of the redistribution scheme and might oppose its introduction based on this belief. Second, free-riders might fear to lose from the introduction of the redistribution scheme and oppose it on these grounds.

To test for the acceptance, or social feasibility, of the redistribution scheme, we implemented a treatment $\mathrm{T}$ (Vote), in which subjects voted on the redistribution option at the beginning of phase 2 . We find that the redistribution scheme is very popular: $73.3 \%$ of subjects voted for the proposal, which translated into 85\% (= 17 out of 20) groups accepting the redistribution option in phase 2. We observe no differences in contribution behavior depending on whether the redistribution option has been exogenously imposed or endogenously accepted [T(Redistribute) vs. T(Vote, accept), $p=0.264$, two-sided Mann Whitney test]. The analogous result holds in the three groups who rejected the proposal.

\section{$5 \quad$ Summary and conclusion}

This paper has shown that the provision of public goods improves substantially with pure redistribution. Redistribution has an immediate positive effect on economic efficiency because money is redistributed from low contributors to high contributors. When asked to vote on the option to redistribute, we find that the redistribution scheme is popular.

It is worthwhile to emphasize similarities and differences of our design compared to the use of redistribution aimed at improving cooperation in mechanism design. Imposed redistribution rules have been suggested as a device to sustain full cooperation in equilibrium (Falkinger 1996), and experimental research has shown that such a mechanism induces behavior 
in line with the theoretical predictions (Falkinger, et al. 2000). An important difference between the Falkinger mechanism and our scheme is that the former has a fixed exogenous sanction and reward structure for deviations from the average group contribution. In contrast, our scheme has an endogenous relation between contributions, rewards, and sanctions. It seems that subjects in our experiment use redistribution similarly as in the exogenously imposed redistribution rule in Falkinger. This observation suggests that the Falkinger mechanism proposes an intuitive and behaviorally relevant rule, and this behavioral feature may be an important reason why the exogenously imposed rule for redistribution of the Falkinger mechanism leads to efficient outcomes.

\section{References}

Falkinger, J. (1996): Efficient Private Provision of Public Goods when Deviations from Average are Rewarded. Journal of Public Economics 62: 413-22.

Falkinger, J., E. Fehr, S. Gächter, and R. Winter-Ebmer (2000): A Simple Mechanism for the Efficient Provision of Public Goods - Experimental Evidence. American Economic Review 90(1): 247-64.

Fehr, E. and S. Gächter (2000): Cooperation and Punishment in Public Goods Experiments. American Economic Review 90(4): 980-94.

Sefton, M., R. Shupp, and J. Walker (2002): The Effect of Rewards and Sanctions in Provision of Public Goods. Working Paper. University of Nottingham and Indiana University. 